\title{
Distortion and Mechanical Characteristics of Single-V and Single Bevel Welded Low Carbon Steel
}

\author{
Muhamad Hellmy Hussin, NurAzida CheLah
}

\begin{abstract}
Welding is a fabrication or sculptural process that joints the materials, usually metals or thermoplastics, by inducing fusion. It is as distinct process from lower temperature metal-joining techniques such as brazing and soldering, to high temperature welding process and this process keep the base metal from melted. In addition, to melt the base metal, a filler material is typically added to the joint to form a pool of molten material that cools at room temperature, forming a joint that is usually stronger than the base material. Pressure may also be used along with heat, or by itself, to produce a weldment. The current study presents the effects of distortion that occurred in single- $V$ and single bevel welded mild steel. It also includes the macro and microstructure analysis, mechanical properties and also the consumable usage along the time needed to complete the bevel and welding process. As a result, single- $V$ is way more safe and reliable to use to withhold large load compare to single bevel.In term of financial, single bevel way more ahead.
\end{abstract}

Index Terms: single- $V$ weld, single bevel, distortion, mechanical, microstructure.

\section{INTRODUCTION}

Welding is a fabrication or sculptural process that joints the materials, usually metals or thermoplastics, by causing fusion, which is distinct from lower temperature metal-joining techniques such as brazing and soldering to high temperature welding. The process of joining which do not melt the base metal require a filler material to be added during joining process to form a pool of molten material that cools at room temperature. The joint produced typically has high strength than the base material. Instead of that, pressure may also be used along with heat, or by itself, to produce a weld [1].

Carbon steel is the most widely used in engineering material, accounts for approximately 85\%, of the annual steel production worldwide. Despite its relatively limited corrosion resistance, carbon steel is used in large tonnages in marine applications, nuclear power and fossil fuel power plants, transportation, chemical processing, petroleum

Revised Manuscript Received on February 21, 2020.

* Correspondence Author

Muhamad HellmyHussin*, Fabrication \& Joining, University of Kuala Lumpur Malaysia France Institute (UNIKL MFI), Selangor, Malaysia.

NurAzidaCheLah, Fabrication \& Joining, University of Kuala Lumpur Malaysia France Institute (UNIKL MFI), Selangor, Malaysia.

(C) The Authors. Published by Blue Eyes Intelligence Engineering and Sciences Publication (BEIESP). This is an open access article under the CC BY-NC-ND license (http://creativecommons.org/licenses/by-nc-nd/4.0/) production and refining, pipelines, mining, construction and metal-processing equipment [2].

It is important to note that, the loads in a welded structure are transferred from one member to another through the welds placed in the joints. Combinations of welds may be used to connect a joint, depending upon the strength requirements and loading conditions. For example, fillet and groove welds are frequently combined in corner and T-joints. Welded joints are designed primarily to meet the strength and performance requirements for the service conditions under which they must perform. The manner in which the stress will be applied in service whether in tension, compression, shear, bending, torsion, or a combination of these must be also beconsidered. When designing for fatigue, different joint details may be required. In addition, joints should be designed to avoid stress raisers and minimize the residual stresses. Conditions of corrosion or erosion are one of the main consequences that require joints that are free of irregularities, crevices, and other areas that make them susceptible to such forms of attack. Certain welding processes, in conjunction with certain related types of joints, have repeatedly provided satisfactory performance in metal's joining $[3,4]$.

Joint design such as butt welds is welds where two pieces of metal to be joined are in the same plane. These types of welds require only some preparation and are used with thin sheet metals that can be welded with a single pass. Common issues that can weaken a butt weld are the entrapment of slag, excessive porosity, or cracking. In order to get strong welds, the goal is to use the least amount of welding material as possible. Butt welds are prevalent in automated welding processes, such as submerged-arc welding (SMAW), due to their relative ease of preparation. When metals are welded without human guidance, there is no operator to make adjustments for non-ideal joint preparation [5-7].

Additionally, a proper weld strength for a CJP (Complete Joint Penetration) groove weld is achieved by having complete weld fusion and by using the correct strength filler metal. The size of the weld does not determine weld strength. Rather, weld size is simply the resulting volume of weld metal necessary to fill in the joint of the proper dimensions. Proper joint dimensions are those which allow enough access of the electrode into the joint so that good welding techniques can be used to achieve complete fusion with the base plates $[8,9]$. 
In industries nowadays for example like hull structure or pipeline, they prefer to use single- $\mathrm{V}$ joint because its strong but it will consume high cost and time for edge preparation and filler metal usage. Based on statement above, single bevel way more cheaper and consume less time for edge preparation and filler metal usage. This study will produce a data on why industries preferred to use single- $\mathrm{V}$ instead of single bevel [10]. The current paper presents the study of distortion effects that occurred in single- $\mathrm{V}$ and single bevel welded mild steel. It includes the micro and macrostructure analysis, mechanical characteristics and also the consumable usage along the time needed to complete the bevel and the welding process.

\section{MATERIALS AND METHODS}

\section{A. Material Preparation}

A36 or also known as mild steel has a density of 7,800 $\mathrm{kg} / \mathrm{m} 3(0.28 \mathrm{lb} / \mathrm{cu}$ in). Young's modulus for A36 steel is 200 GPa (29,000,000 psi). It has a Poisson's ratio of 0.26 , and a shear modulus of $75 \mathrm{GPa}(10,900,000 \mathrm{psi})$. Plates thicker than 8 in have a 32,000 psi (220 MPa) yield strength and the same ultimate tensile strength of 58,000-80,000 psi (400-550 MPa).

For single-V and single bevel joint design, a groove angle of $60^{\circ}$, root face thickness of $3 \mathrm{~mm}$ and a root opening of $2 \mathrm{~mm}$ gapare shown in Fig. 1 and 2. Table 1 show the chemical composition of the mild steel.

Table 1.Element compositions in wt \% of mild steel

$\begin{array}{llllllll}C & \text { Si } & \text { S } & \text { Cu } & \text { Mn } & \text { P } & \text { Fe }\end{array}$

\begin{tabular}{lllllll}
\hline 0.29 & 0.28 & 0.05 & 0.20 & 1.03 & 0.04 & 98.0 \\
\hline
\end{tabular}

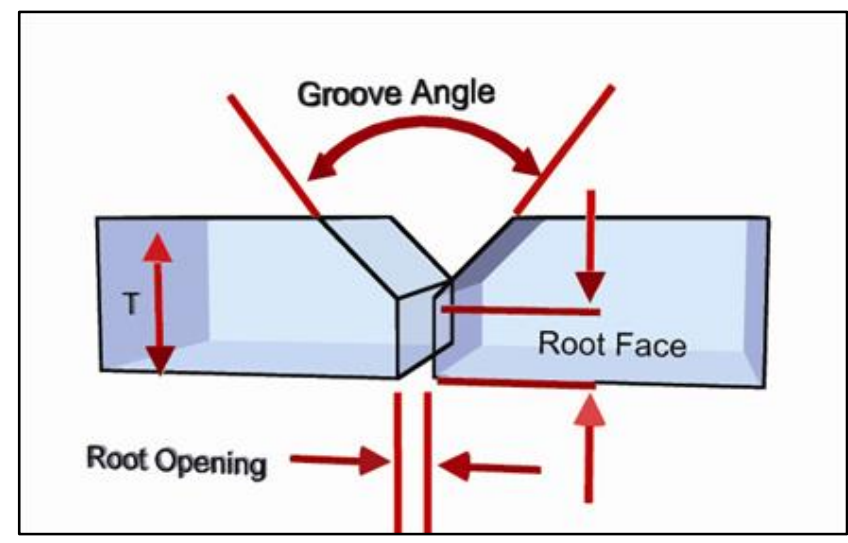

Fig.1 Single-V joint design

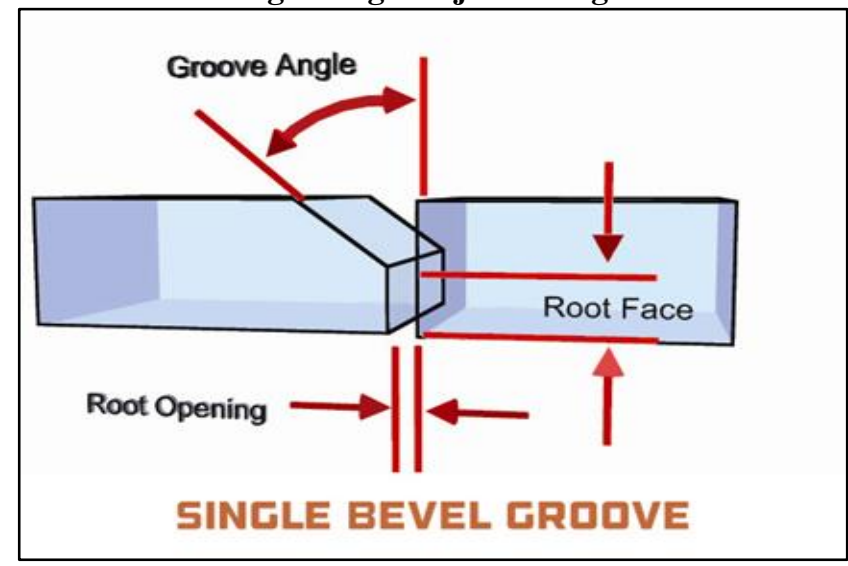

Fig. 2 Single bevel joint design

Table 1 Parameter SMAW for single-V

\begin{tabular}{|c|c|c|c|c|c|}
\hline \multicolumn{7}{|c|}{ Shield Metal Arc Welding } \\
\hline Pass/Layers & Travel speed (mm/s) & $\begin{array}{c}\text { Current } \\
\text { (AMP) }\end{array}$ & Voltage (V) & Electrode & Size Electrode \\
\hline Root pass & 2.82 & $90-100$ & $20-27$ & E7018 & 2.5 \\
\hline Second pass & 1.88 & $80-90$ & $20-27$ & E7018 & 3.2 \\
\hline Third pass & 2.01 & $80-90$ & $20-27$ & E7018 & 3.2 \\
\hline Capping & 2.21 & $80-90$ & $20-27$ & E7018 & 3.2 \\
\hline
\end{tabular}

Table 2 Parameter SMAW for single bevel

\begin{tabular}{|c|c|c|c|c|c|}
\hline \multicolumn{7}{|c|}{ Shield Metal Arc Welding } \\
\hline Pass/Layers & Travel speed (mm/s) & $\begin{array}{c}\text { Current } \\
\text { (AMP) }\end{array}$ & Voltage (V) & Electrode & Size Electrode \\
\hline Root pass & 1.91 & $75-80$ & $20-27$ & E7018 & 2.5 \\
\hline Second pass & 2.04 & $80-85$ & $20-27$ & E7018 & 3.2 \\
\hline Capping & 2.18 & $80-85$ & $20-27$ & E7018 & 3.2 \\
\hline
\end{tabular}




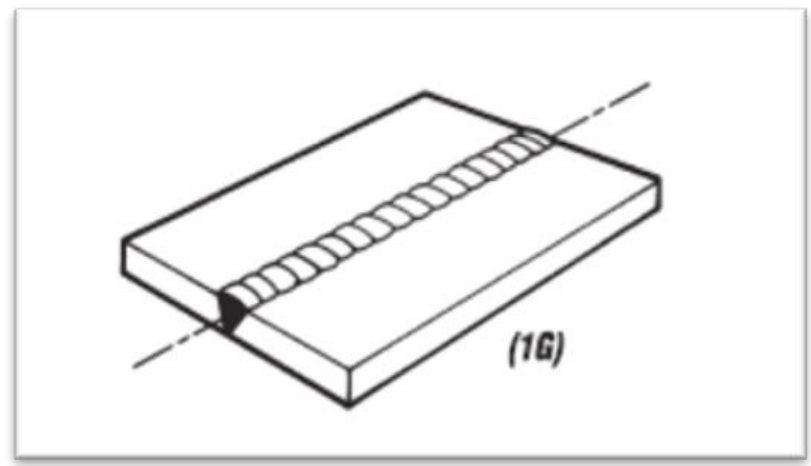

Fig. 3 Flat welding position

\section{B. Welding Parameters and Visual Inspection}

There are only one welding position will be utilized for the project which is flat position (1G). This experimental work required Shielded Metal Arc Welding (SMAW) to complete the joint. As electricity passes through the electrode, the flux forms a gas, which shields the electric arc in the space between the electrode and the metal being welded, preventing contamination and debris from atmospheric gasses in the weld. This process is fairly simple and doesn't require much in the way of specialized equipment, making it very popular.

\section{Mechanical Testing and Morphology Analysis} difference of macro and microstructure between single- $V$ and single bevel welded joint. The visual inspection was also conducted on the weldment after complete the welding process on the single- $\mathrm{V}$ and single bevel welded joint to ensure the specimen are suitable and fit to perform macro and microstructure analysis.

Carrying out macro and microstructure is either to cut to specific size or mounted in a resin mound and then polished to a mirror finish and usually etched in an appropriate chemical substance solution before examination. The specimen for this examination will be carried out according to ASME XI. Once the marking is carried out, the specimens were subjected to cutting process according to the marking made.

Tensile and bend test are used to evaluate the breaking strength and ductility of a material and to determine that the material meets the specification requirements. For tensile test, a specimen is ruptured by a test machine while the actual force and the elongation of the specimen are measured. The most important characteristic values which are determined by this test are yield stress and tensile strength. To determine the deformability of a weld, a bending test was used. Hardness test is performed to identify the hardness of the metal at specific area such as heat-affect zone (HAZ), base metal (BM) and fusion zone (FZ) under microscopic view to make a determination of the tensile strength. Hardness test could also to indicate when the material hardness start changing from ductile to brittle due to greater heat input.

\section{RESULTS AND DISCUSSION}

\section{A. Angle of Distortion}

Fig. 1 shows the difference in angle of distortion between two types of butt joint which are single- $\mathrm{V}$ and single bevel welded joint. The angle was measured by 1800 protector after
Morphology analysis is conducted to determine the

the weld process is completed. When the welding process is performed, the specimen was free from any clamp tools. Since welding involves high heat to fuse the material, there are stresses distributed and generated along the way of the weldment. Because of expansion and contraction of the heated outcome of the material, stresses would be created around the cold parent material when the pool of weld is formed due to thermal expansion.

For single-V welded joint as shown Fig. 1, the value of distortion angle is higher compared to single bevel welded joint. As compare to single bevel joint, a higher distortion angle of single- $V$ welded jointwas found due to a high reading value of groove angle. It is related to weld volume which indicates the contraction and expansion experienced by the specimen was also high. Instead of that, the number of weld runs also becomes one of the factors that contribute to the increasing value of distortion angle. Since the single-V welded joint need many runs of weld to complete the fill, therefore, the value of distortion is higher compared to single bevel welded joint.

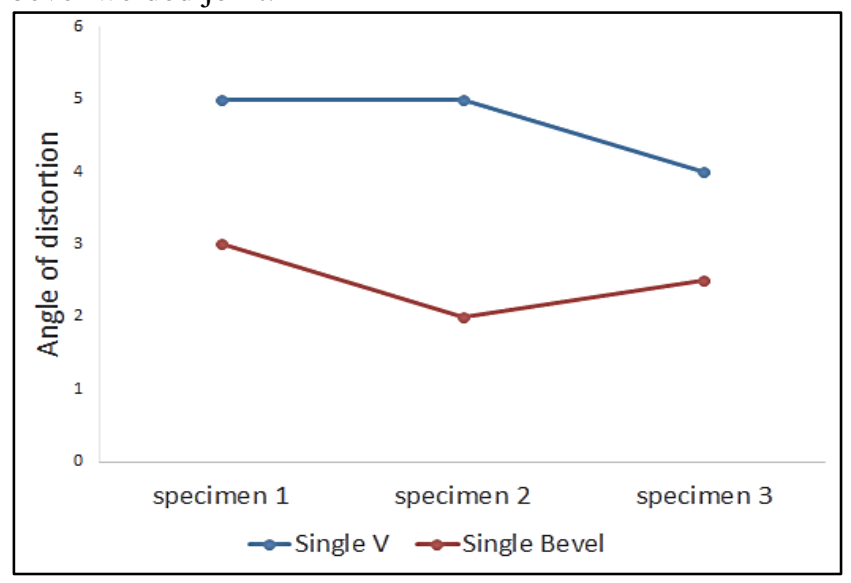

Fig. 1 Angle of distortion between single- $\mathrm{V}$ and single bevel welded joint

For single bevel welded joint (Fig. 1), it shows that the value of distortion angle is low compared to single-V welded joint. This is due to the low reading of groove angle. It can be said that, the low value of groove angle is related to the less experienced with contraction and expansion during welding process. Moreover, the single bevel welded joint doesn't need much run of welds like single- $\mathrm{V}$ to complete the fusion. That's why the value of distortion of singlebevel welded joint is low compared to single- $\mathrm{V}$ welded joint.

Meanwhile, it is suggested in previous study that the distortion can be prevented or atleast can be reduced by considering like reducing volume of weld metal and reducing number of runs. Based on the result, it shows that a single bevel welded joint used less volume of weld metal and less number of run which leads to lower value of angle distortion compared to single- $\mathrm{V}$ welded joint.

\section{B. Consumable Usage to Complete the Bevel and Welding Process}

Single-V and single bevel welded joints have different characteristics especially time consumption to complete the beveling process, time needed for weld completion, electrode usage and costing. 
Time needed for beveling process during single- $\mathrm{V}$ welding preparation is about 110 sec and for single- $V$ welded joint is about 55 sec. Both specimens' dimension is $200 \mathrm{~mm} \mathrm{x}$ $100 \mathrm{~mm} \times 9 \mathrm{~mm}$.

The time taken for these two types of joint design were recorded in order to measure the time to complete the weld runs fora $200 \mathrm{~mm}$ length base metal plates. It was found that the time taken for each joint designswere different in terms of layer's amount. It is indicated that single-V welded jointrequire 4 layers in order to complete the fusion which areone layer of root, second and third layer for hotpass and the fourth layer is for capping. Meanwhile, the single bevel welded jointrequire 3 layers to complete the fusion which includesone layer of root, second layer for the hotpass and the third layer for capping.

Based on the recorded time taken in Table 2 and 3, the single bevel welded jointdoesn't requirelonger duration to complete the weld process. For example, one specimen only requires an average of 1.95 min to complete the first layer at the root. For the second layer which is hotpass, one specimen only require an averageof $2.06 \mathrm{~min}$. Meanwhile, for the final layer which is capping, the average needed is about $2.14 \mathrm{~min}$ to complete the fusion.

For single-V welded joint as shown in Table 3, the recorded average time taken to complete the weld shows longer duration compared to single bevel welded joint. For the first layer which is root, specimen requires about $2.03 \mathrm{~min}$ to complete the fusion. For second layer which is hotpass 1, specimen require about $1.94 \mathrm{~min}$ and the third layer which is hotpass 2, it requires about $2.21 \mathrm{~min}$. For the last layer which is the capping, specimen require about $2.31 \mathrm{~min}$ to complete the fusion. From the result, it shows that single bevel welded joint did not require longer duration to complete the weld process because of the weld volume is low compared to single- $\mathrm{V}$ welded joint.

Table 2.Recordedaverage time taken for Single Bevel in minutes

\begin{tabular}{|c|c|c|c|}
\hline \multicolumn{3}{|c|}{ SINGLE BEVEL (in minutes) } \\
\hline \\
\hline
\end{tabular}

Table 3.Recordedaverage time taken for Single-V in minutes

\begin{tabular}{|l|c|c|c|c|c|}
\hline \multicolumn{9}{|c|}{ SINGLE V (in minutes) } \\
\hline & Root & Hot 1 & Hot 2 & Capping & Total \\
\hline Specimen (average) & 2.03 & 1.94 & 2.21 & 2.31 & 8.49 \\
\hline
\end{tabular}

Table 4.Cost estimation for single bevel welded joint

\begin{tabular}{|c|c|c|c|}
\hline \multicolumn{3}{|c|}{ Single Bevel } \\
\hline Root & Hot 1 & Capping & Labour cost \\
\hline RM0.68 & RM0.93 & RM1.11 & RM1.44 \\
\hline
\end{tabular}

Table 5.Cost estimation for single- $V$ welded joint

\begin{tabular}{|c|c|c|c|c|c|}
\hline \multicolumn{5}{|c|}{ Single-V } \\
\hline Root & Hot 1 & Hot 2 & Capping & Labour cost & Total \\
\hline RM0.68 & RM 1.30 & RM1.10 & RM1.48 & RM1.88 & RM6.44 \\
\hline
\end{tabular}

According to the Table 4 and 5 , it shows that cost estimation for single bevel is way cheaper than single-V welded joint because single bevel used two electrodes (E7018 2.5mm) for penetration that cost RM0.68. For one hotpass in single bevel welded joint, the used of 2.5 electrode
(E7018 3.2mm) that cost RM0.93 while capping used 3 electrode (E7018 3.2mm) that cost RM1.11. Estimated labour cost is about RM14.00 per hour. 
Meanwhile, in order to complete the single bevel welded joint, the welder require 6.13 minutes which means it will cost around RM1.44. The total estimate to complete the singlebevel specimen is about RM4.16. On the other hand, the cost needed to complete the single- $\mathrm{V}$ welded joint, the welder require 8.16 with the cost about RM1.88. The total cost estimation to complete a single- $\mathrm{V}$ specimen is around RM6.44.

\section{Macro and Microstructure Analysis for Single-V Welded Joint}

Fig. 2 shows the microstructure image of single- $V$ welded joint. The heat-affected zone (HAZ) is the area of base material, either a metal or a thermoplastic, which is not melted and has had its microstructure and properties altered by welding or heat intensive during cutting operations. The heat input from welding process was found uniformly distributed on single- $V$ welded joint. As shown in Fig. 2, the size of HAZ is small and nearly has the same sizes side to side. The thickness of material also plays an important role and become an important factor that contributes to the size of HAZ.Meanwhile, it is also can be suggested that agood weld penetration for single- $\mathrm{V}$ welded jointmainly at the fusion zone and root of the specimen was found clearly due to the uses of DCEP polarity from the beginning of weld process until the weld fully completed. The DCEP is known as the best weld characteristic because in DCEP, the electricity flows into the tip of the welding rod and concentrates about two-thirds of the heat, which gives good weld penetration. DCEP is usually used on thicker steels. Electrode E7018 and the weave technique also become important factors that contributedto good weld characteristics [11-13].
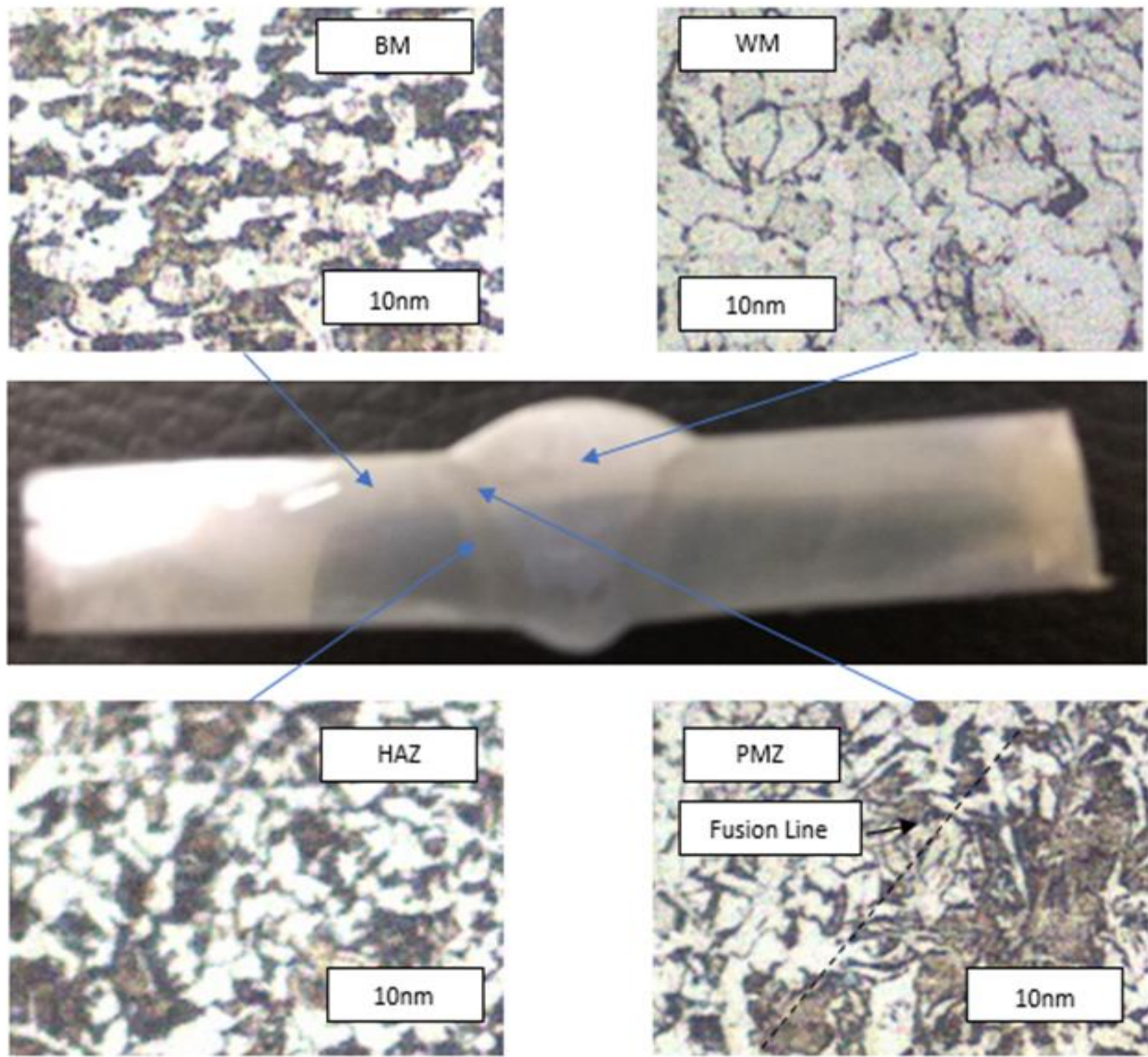
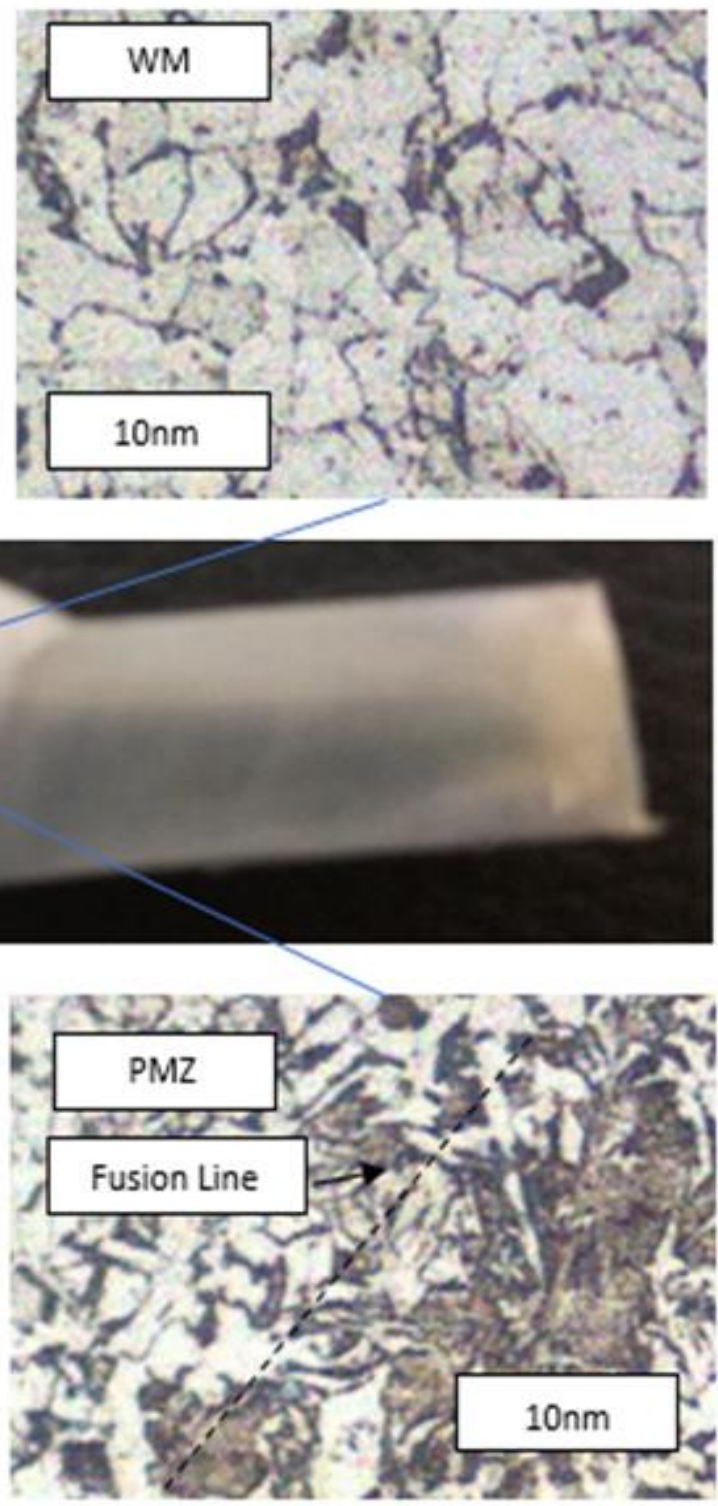

Fig. 2.Macro and microstructure image of single- $V$ welded joint

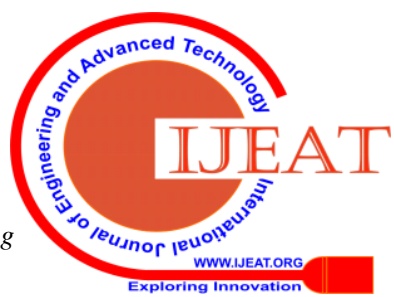




\section{Macro and Microstructure Analysis for Single Bevel Welded Joint}

Fig. 3 showsthe macro and microstructure image of single bevel welded joint. It can be suggested that the heat input from welding processwas non-uniformlydistributed on the single bevel welded joint. As shown in Fig. 3, the size of HAZ on bevel area is larger compared to single- $V$ welded joint. This is because the heat is more focused to bevel area compare to the non-bevel area.

For the penetration on fusion zone, the weld was found did not show well penetration although the DCEP polarity and electrode E7018 were used. This is because the narrow groove of weld where the weaving technique cannot be applied.Instead of that, the width groove weld shows well penetration. Moreover, for root penetration for single bevel specimen, it shows to have an excess penetration which is caused by narrow gap and excessive heat input.

For single bevelbead width, it shows quite similar findings with the single-V welded joint which shows largerbead width, thus provide a flatter bead height. According to the Fig. 3, it shows that at the base metal (BM) area, the white areas are solid solution known as ferrite, normally related to low strength, soft and very ductile component of low carbon steels. Ferrite is almost pure iron with a minimum amount of carbon dissolved in it. The dark grey areas are actually a composite called Pearlite.

The properties of pearlite are good strength, hardness and toughness. This show that's the heat not much affects the base metal microstructure because it remains like the original grain structure. The base metal image of single bevel welded joint shows similar behavior with single-V welded joint.

At HAZ area is commonly related with the presence of martensitic. It is indicated or possess as hardness in respect of mechanical properties. Martensitic is desirable for application like tool and die parts $[14,15]$. However, to much martensitic structure may affect the strength of the mechanical properties and the material tend to be in brittle behaviour. The grain structure was coarse as the bigger size of pearlite shown. This usually weakened the structure of at this region.

At partial melted zone (PMZ), it shows that the bevel area received more heat and tends to form a large size of pearlite structure. The grain structure between these two shows changes in terms of sizing of the boundary. HAZ shows boundary that are much coarse compared to fusion zone and this is due to the area being affected by heat during the fusion. However, the fusion zone shows grain that is much finer due to the properties better than the base metal itself.

Meanwhile, at fusion zone, the amount of ferrite and pearlite structure becomes small due to heat applied during weld process. These grain structures are preferred to be used for application that requires hard and tough materials.Based on the microstructure result comparison of this two type of joint design which is single $\mathrm{V}$ and single bevel, there different image of HAZ, PMZ and weld metal between two of them except for base metal.
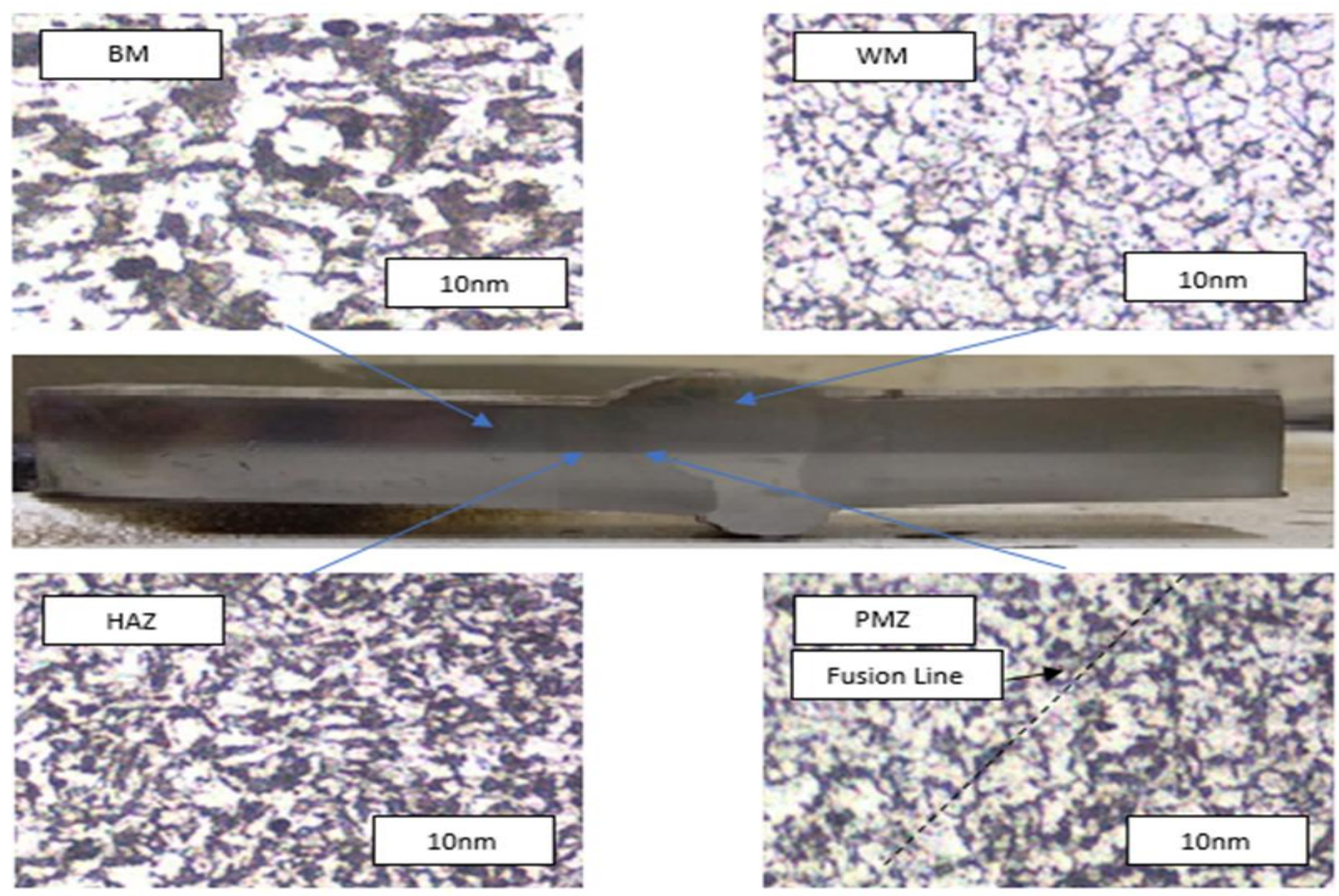

Fig.3.Macro and microstructure image of single bevel welded joint 
The observation at base metal image, single $\mathrm{V}$ and single bevel have quite similar arrangement of the grain structure because this region doesn't affected much by heat. High heat input applied on HAZ for single bevel welded joint caused distribution ofsmallgrain compared with single- $\mathrm{V}$ welded joint that has larger size of grain due to uniformly heat distributed. For the fusion zone, the grain structure of single-V welded joint shows larger grain size compared to single bevel.

\section{E. Hardness}

According to Fig. 4, the hardness test result is performed by using Vickers hardness test machine. Based on graph, the base metal strength of hardness starting from point 1 is 159.1 following by point 2 is 153.0 and point 3 which is 147.5 . From this value shows that base metal at single- $V$ shows less difference compared with single bevel welded joint.
162.3 followed by point 2 which is 195.0 and 198.4 for point 3 . The value at this region quite different compared to single bevel welded joint due to smaller HAZ area that caused by uniformly heat distribution. For the fusion zone, the hardness value start to decrease where the value of point 1204.5 followed by point 2187.8 and point 3 is 201.6. This is also because of the mixture of composition between electrode and base metal during the weld process.

It also shows that the change to brittle properties due to the specimen received high heat input during welding process and this can be proved by the high value of hardness. Single-V welded joint was found to be more ductile as the value of hardness is low compared to single bevel welded joint. It is caused by the heat that is uniformly distributedduring the welding process and formed small size of HAZ area.

At heat affected zone (HAZ) region, the value for point 1 is

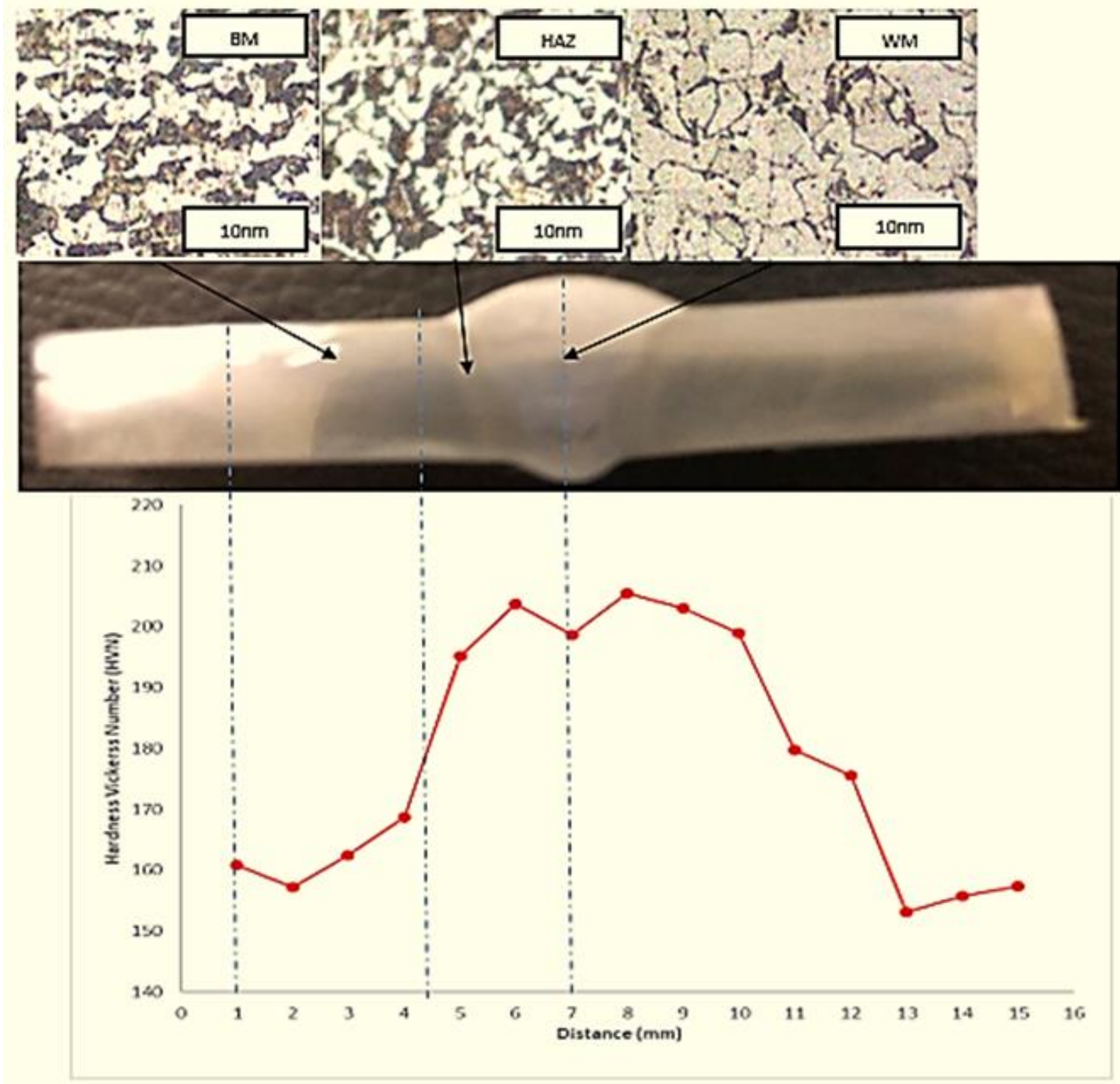

Fig. 4.Hardness graph of single-Vwelded joint 


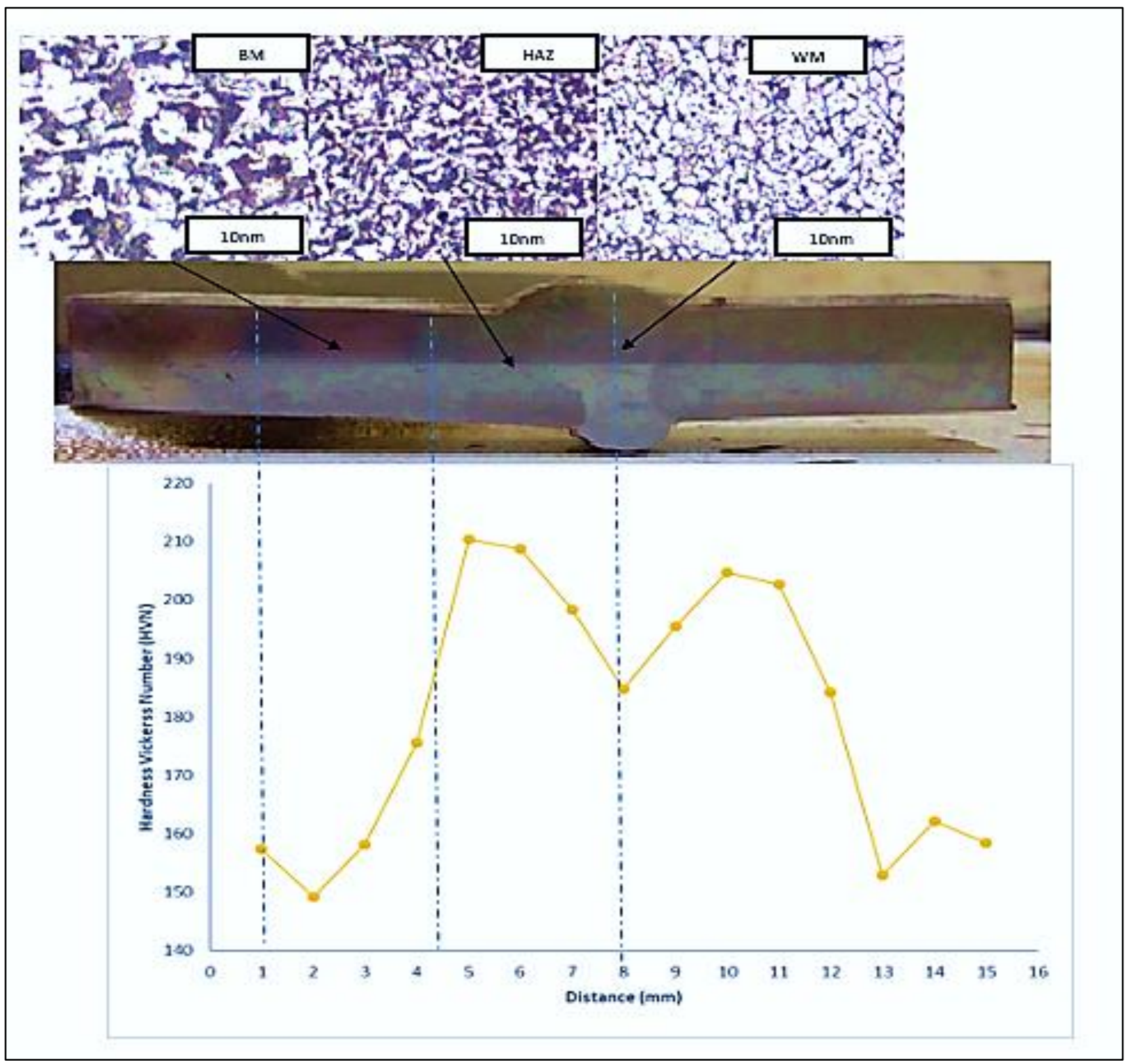

Fig. 5.Hardness graph of single bevelwelded joint

Fig. 5 shows the hardness test result. It shows that the base metal strength of hardness starting from point 1 is 157.4 following by point 2 is 149.2 and point 3 which is 158.1 . From this value, it shows that the base metal at single bevel welded joint was found not much affected by generatedheat. At HAZ region, the value for point 1 is 175.6 followed by point 2 which is 210.4 and 205.8 for point 3 . The value at this region quite high due to the beveled area receiving too much heat that change the material into brittle properties. For the fusion zone, the hardness value start to decrease where the value of point 1 is 198.4 followed by point 2, 184.8 and point 3 , is 195.5. This is because the mixture of composition between electrode and base metal.

\section{F. Bend Test}

Bend test has been conducted after the completion of welding process and the specimen has been marking and cutting according to welding standard code. The bend test is a simple and inexpensive qualitative test that can be used to evaluate both the ductility and soundness of a material. It is often used as a quality control test for butt-welded joints, having the advantage of simplicity of both test piece and equipment.

From the finding in Fig. 6, the value of maximum stress before the fracture occurred for single bevel welded joint is lower compared to single- $\mathrm{V}$ welded joint. The maximum value for single bevel welded joint is low because HAZ area in bevel area is large which mean it is more easier to fracture when bend test is conducted. For single- $\mathrm{V}$ welded joint, the maximum value is high due to uniform heat distribution that led to smaller size of HAZ area which means it takes high stress until its fractured. According to the ASME IX standard for the bend test requirement, if the sample indicate fracture zone at any area of weldment or sample the result of the testing would be rejected.

Published By:

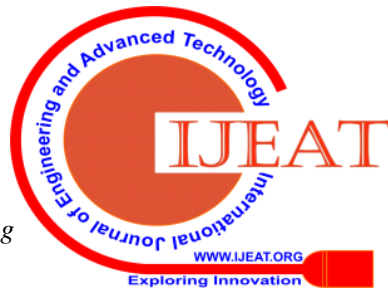




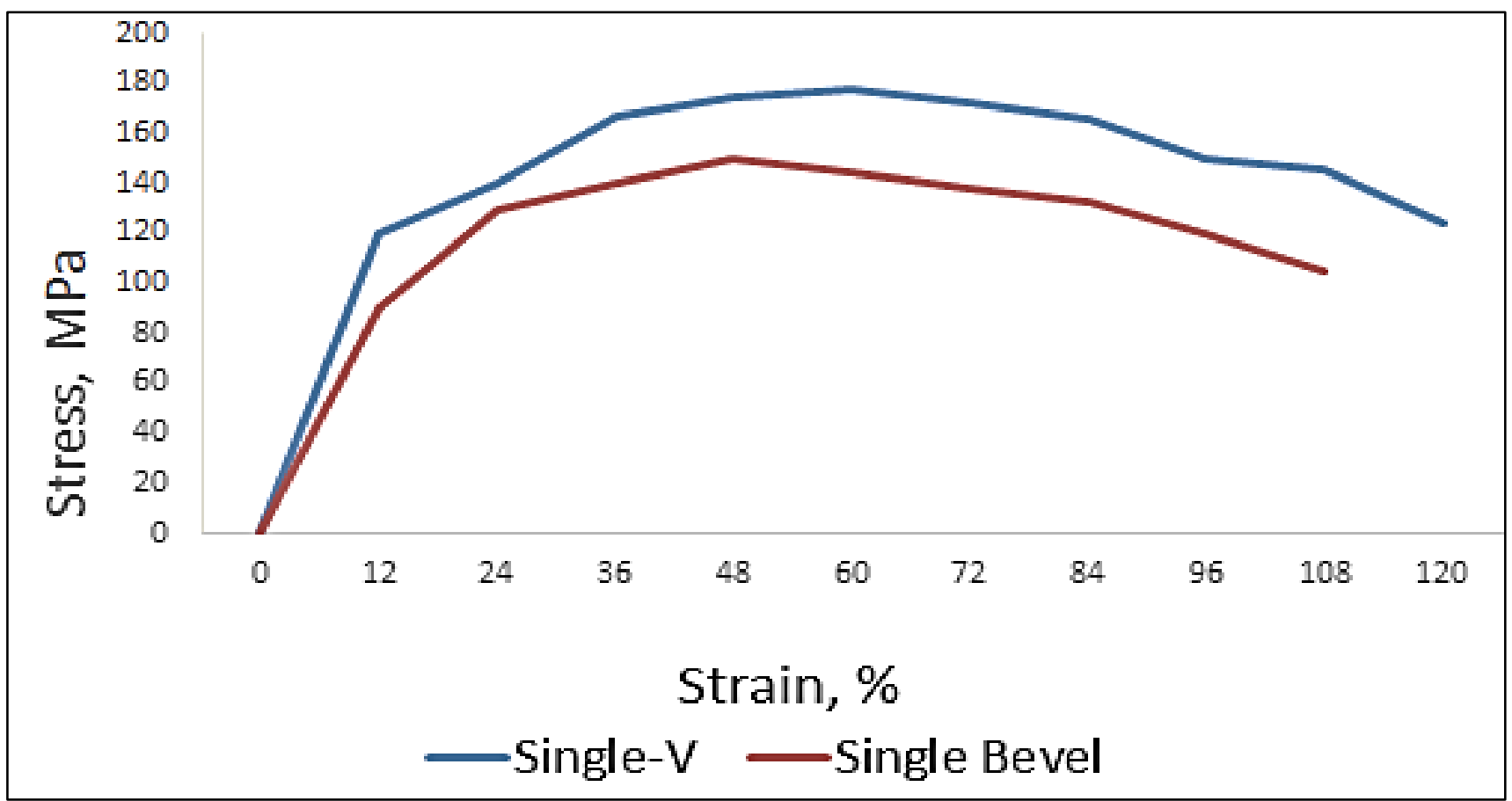

Fig.6: Bend testing result for Single-V and Single Bevel

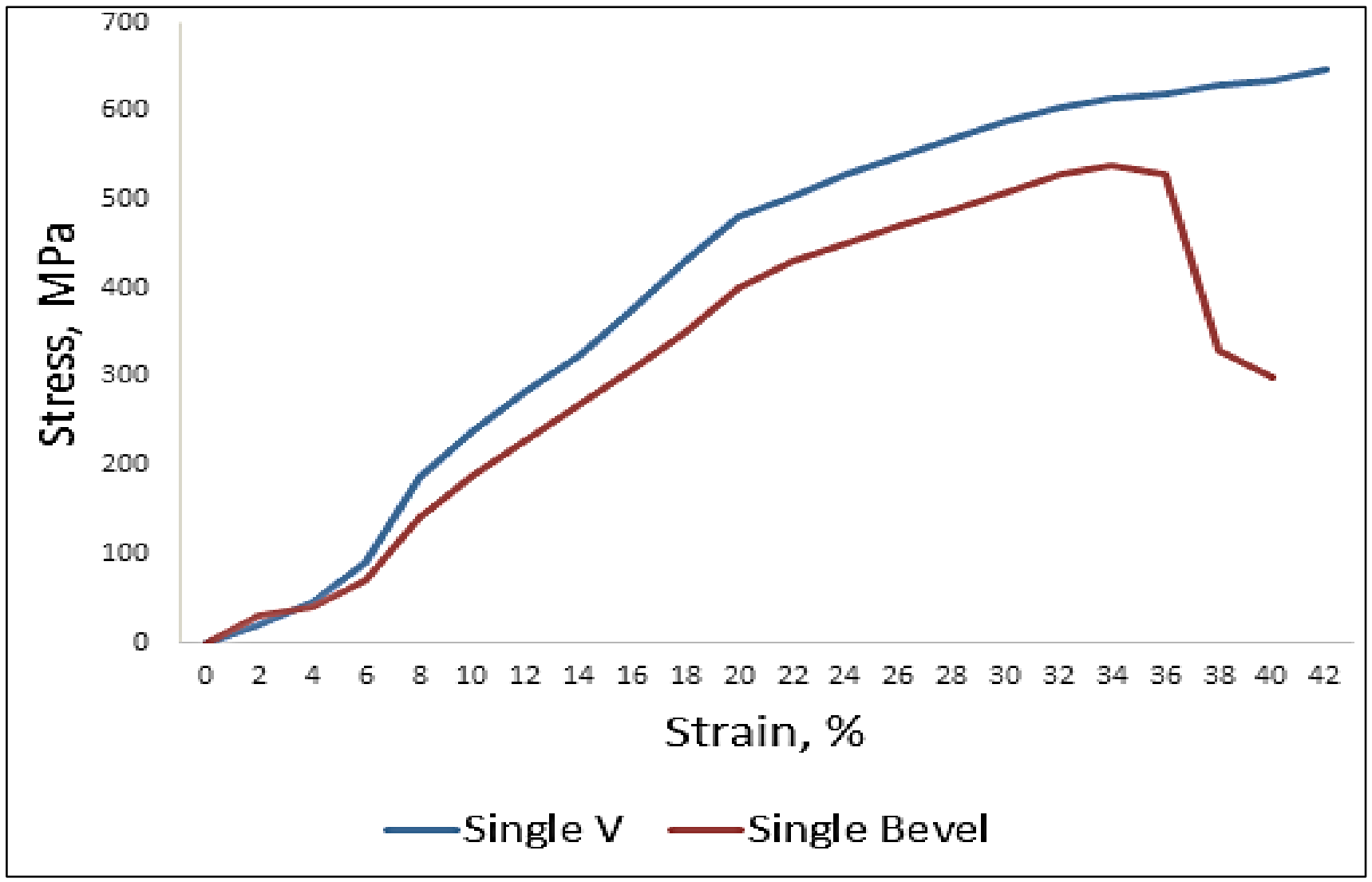

Fig. 7: Tensile testing result for Single-V and Single Bevel

\section{G. Tensile Test}

According to the stress-strain graph in Fig. 7, the result after conducted the test show that single bevel welded joint has total of $35 \%$ of ultimate strain and 540MPa of ultimate stress. From the stress strain curve, it is indicated that, a single bevel welded joint not only have low ultimate tensile strength but also low strain (ductility) compared to single-V welded joint. This low strain generally related with larger size of HAZ on bevel area that tends to harden the specimen and change its mechanical properties. On the other hand, it shows that for single- $\mathrm{V}$ welded joint, the specimen has total of $43 \%$ of ultimate strain and 647MPa stress. This indicated that single- $\mathrm{V}$ welded joint not only have high strain but also high ultimate tensile strength compared to single bevel welded joint. 
This is because theheat was well distributed during the weld process that contributed to smaller HAZ area for the single- $\mathrm{V}$ welded joint.

According to Fig. 7, single-V welded jointshows the breaking area at BM region. This shows that the ductility of the sample is high and also can be proven by the value of the hardness. It is well indicated that the single- $\mathrm{V}$ welded joint can withstand higher load. Meanwhile, for single bevel welded joint, one sample break at the base metal, one sample break at the weldment and the other two sample break at the HAZ of bevel area. It can be concluded that the ductility at the bevel area decrease compared to single-V welded joint. Therefore, it shows that the single bevel welded joint could not withstand higher load compared to single- $\mathrm{V}$ welded joint.

\section{CONCLUSION}

Single bevel welded joint might be cheaper and save a lot of time compared to single- $\mathrm{V}$ welded joint. In terms of financial, single bevel welded joint way more ahead. From the study, it shows that the single- $\mathrm{V}$ welded joint is way more safe and reliable to use and can withhold large load compared to single bevel welded joint. In terms of safety and sustainability, it is way more important than thinking about save cost and time.

\section{REFERENCES}

1. O'Brien, A. (2004). Arc cutting and Gauging. In T. W. Committee AWS Welding handbook, 9th edition, volume 2 (p. 654). Miami: American Welding Society.

2. Kobe Steel, LTD. (2008, April). Welding Consumables. Retrieved from Kobelco Welding Handbook: http://www.kobelco.co.jp/english/welding/files/handbook2016.pdf

3. AWS. (2004). Acceptance Criteria; Method of Testing. In AWS, AWS D1.1/ D 1.1M:2004 (pp. 152-167). USA: AWS

4. Bringas, J. E. (2003). Casti Metal Blue Book Welding Filler Metal. Alberta: Casti Publishing Inc.

5. Electric, T. L. (2014). Weld Fusion vs. Weld Penetration. Retrieved from http://www.lincolnelectric.com.

6. Homestead. (n.d.). Shielded Metal Arc Welding. Retrieved from http://hvacrknowlagecenter.homestead.com/Stick_Welding.pdf:

7. Khan, M. I. (2007). Welding Science and Technology. New Delhi: NEW AGE INTERNATIONAL PUBLISHER.

8. ASME. (2007, December 7). public.resource.org,inc. Retrieved from https://law.resource.org/pub/us/code/ibr/asme.b31.1.2007.pdf:

9. AkinolaAdebisi, Kayode Joseph, OyetunjiAkinlabi . (2016). Effect of Bevel Angles and Heat Input on Hardness Property and Microstructures of Mild Steel Weldments . International Journal of Materials Science and Engineering.

10. Hicks, J. (2001). Welded Design: Theory and Practice. New York: Woodhead Publishing.

11. MD Anis Raza (2016) 'the effect of weld position on mechanical properties of tmt rod joined by arc welding', International Journal of Research in Engineering and Technology, 05(09), pp. 71-75. doi: 10.15623/ijret.2016.0509010

12. Talabi, S.I., Owolabi, O.B., Adebisi, J.A. and Yahaya, T. (2014) 'Effect of welding variables on mechanical properties of low carbon steel welded joint', Advances in Production Engineering \& Management, 9(4), pp. 181- 186. doi: 10.14743/apem2014.4.186.

13. Wan Muda, W.S.H., Mohd Nasir, N.S., Mamat, s., and Jamian, S (2015). Effect of welding heat input on microstructure and mechanical properties at coarse grain heat affected zone of abs grade a steel.

14. D.Gandhi. (2007, March). Carbon Steel Handbook, 1.

15. B.Aydemir, B. S. (2011). Material Hardness. The Advantage of New Generation Hardness Measurement Methods, 337.

\section{AUTHORS PROFILE}

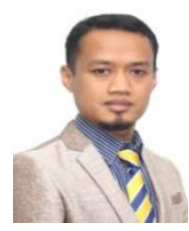

Muhamad Hellmy Hussin, is a lecturer in University of Kuala Lumpur Malaysia France Institute (UNIKL MFI) located at Bandar BaruBangi, Selangor for fourteen years. His expertise is in Innovation and Engineering Design, and also in Corrosion and Failure Analysis. He did his Bac. (Hons.) in Industrial Production Management at the University Nice Sophie Antipolis (UNSA), France, and then pursued his Master Degree in Innovation and Engineering Design at University of Putra Malaysia (UPM) Serdang, Selangor.Over the last eight years he becomes involved in welding and joining research works. And since then he has continued his research and involved in Corrosion and Failure Analysis research areas, Corrosion and failure analysis works. Now, he pursue his PhD in (Mechanical), focusing on High Temperature Corrosion in Hot Gases Environment. He has published articles and journals mainly in Welding and Joining, Corrosion degradation and Failure Analysis research works.

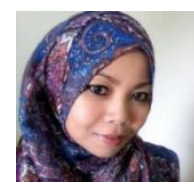

Dr. NurAzida CheLah, is a senior lecturer on Corrosion degradation and Failure Analysis studies at the University of Kuala Lumpur Malaysia France Institute (UNIKL MFI), Bandar BaruBangi, Selangor. She did her Bac (Hons) in Materials Science and then pursued her Master degree in Mechanical Engineering majoring in Fatigue failure Assessment on welded joint at University of Putra Malaysia (UPM) Serdang, Selangor. Her PhD focusing on High Temperature Corrosion Study on Aluminium Welded Joint at The National University of Malaysia (UKM), Bangi, Selangor. And since 2007 she started writing an articles and journals mostly on Fatigue Assessment Analysis, Welding and Joining, Corrosion degradation and Failure Analysis Studies. 